\title{
A comparative study of low multidirectional locked nailing and locking compression plating in management of distal tibia fractures
}

\author{
Balakrishna Pinnaka, Shankarlinga S.*, K. Ramachandra Kamath, \\ Rajashekar Danda, M. Girish Raju
}

Department of Orthopedics, KMC Mangalore, Manipal University, Karnataka, India

Received: 10 September 2018

Revised: 09 October 2018

Accepted: 11 October 2018

\section{*Correspondence:}

Dr. Shankarlinga S.,

E-mail: shankyasajjan@gmail.com

Copyright: (C) the author(s), publisher and licensee Medip Academy. This is an open-access article distributed under the terms of the Creative Commons Attribution Non-Commercial License, which permits unrestricted non-commercial use, distribution, and reproduction in any medium, provided the original work is properly cited.

\section{ABSTRACT}

Background: Ideal management for distal tibial meta-diaphyseal fracture remains controversial, due to lack of adequate evidences about implants and multiple treatment modalities. Most commonly these fractures were dealt with either locking compression plate (LCP) or by multi directional intra-medullary nail (IMIL). Aim is to compare these two implants, to understand the mechanism and find out the ideal implant for the management of distal tibia fractures. Methods: This study is prospective and comparative done at the associated hospitals of KMC Mangalore, spanning a period of around 2 years (October 2014 to July 2016). All patients presented with distal tibial meta-diaphyseal fractures were included in the study. Patients were treated with either low multi directional IMIL nail or by LCP and followed up for a minimum period of 6 months. Outcome measures included Olerud Molander Ankle Score (OMAS), wound issues, union of the fracture and patient mobility.

Results: 50 consecutive patients (mean age 40 years) were included in the study, divided equally into 2 groups. Group-A treated with multi directional IMIL nail and group-B with MIPPO plating. Mean functional OMAS score for nailing is 91 and for plating is 88 . All fractures treated with nailing united within 6 months and $4 \%$ patient treated by plating goes mal union and $4 \%$ infected.

Conclusions: For distal tibial fracture management, intra-medullary nailing proved reliable surgical option with regards to the OMAS score, fracture union and less infection rates.

Keywords: Minimal invasive plating, Olerud Molander ankle score, Intra medullary nailing

\section{INTRODUCTION}

Fractures of the distal tibia meta-diaphyseal region are routinely seen as a consequence of RTA and other high energy trauma, which constitute about $10 \%$ of the fractures of distal end of tibia. ${ }^{1,2}$ These fractures are usually associated with bad soft tissue injury and require surgical management in the form of internal or external fixation. Due to the subcutaneous location of distal tibia, open fractures are more common compared to other long bones. ${ }^{3-7}$ Management of fractures in the distal tibial region are more complicated because of soft tissue injury, which frequently interrupts blood supply to the fracture site and leads to increased rate of complications (infection, non-union or delayed union). ${ }^{8}$ Different modalities of treatment are available: intramedullary (im) nailing, plating and external fixation. During past years, open reduction and plate fixation has attained an agreeable degree of acceptance but it often requires larger incision and soft tissue dissection which increases the risk of complications (infection, non-union, delayed union). ${ }^{8}$ To overcome these drawbacks minimally invasive plating has come into an existence.

Interlocking intra-medullary nailing can be considered as "criterion" for treatment of tibial diaphyseal fractures but 
in distal tibia fractures, it is not so as studies have shown that there is a biomechanical disadvantage in distal tibia fractures treated with interlocking intra-medullary nailing when compared to plate fixation. When fracture is very close to the ankle IMIL nail will give less intrinsic stability as a result of decreased contact between bone and implant. If cortical contact distal to fracture site is less, an excessive amount of mechanical load is carried by the nail and is transferred to the distal screws which leads to bending of screws, hence failure results. ${ }^{9}$ To overcome these bio-mechanical challenges advanced techniques of IM nail are developed i.e. multidirectional locking nail to increase angular stability and poller screws to improve primary stability and alignment of fracture. Plate fixation and interlocking intra-medullary nailing are the most effective methods for distal tibia fractures, but still it's debatable which one will yield better results. So our aim is to evaluate the union time, functional outcome and percentages of complications in plating versus nailing.

\section{METHODS}

This prospective study was done at the associated hospital of KMC Mangalore, between periods of June 2014 to October 2016. Ethical committee clearance was taken from Kasturba Medical College, Mangalore (IEC KMC MLR 11-14/234). The first 50 consecutive patients who presented with distal tibia meta-diaphyseal fractures (as per sample size), and who were willing for surgery were included in the study. The sample size is divided equally into 2 groups based on convenient sampling. Group-A patients were treated with multi directional IMIL nailing and Group-B patients were treated with minimal invasive plating $\{\mathrm{MIPPO}\}$. Inclusion criteria includes: age between 18 to 60 years with closed or Gustilo type 1 or type 2 open extra-articular distal tibia fractures. Patient presenting with intra articular fractures, Gustilo type 3 open fractures and pathological fractures and neglected fractures were excluded. AO classification was used to classify the fracture types and Gustilo Anderson classification for open fractures.

Most of the nails were inserted after reaming the medullary canal and locked with minimum 2 proximal and 3 distal locking screws. Prophylactic antibiotics were given to all patients prior to surgery. All patients were operated by senior surgeons and they were followed up at an interval of $4^{\text {th }}, 10^{\text {th }}, 16^{\text {th }}, 24^{\text {th }}$ week and above, radiological evaluation was done by using anteroposterior and lateral views at 6 weeks intervals. "Malunion is defined as more than $5^{0}$ of angular deformity in any plane or shortening by $1 \mathrm{~cm}$ or more in length" Functional outcome was measured by using self administered patient questionnaire i.e. Olerud Molander ankle score ranges from 0-100, score more than 90 points-excellent, 61 to 90 -good, 31 to 60 - fair and lower than 30 points - poor. ${ }^{10}$

\section{Statistical analysis}

It was executed by an independent statistician who was not involved in the study, group-A (nailing) and group-B (plating) were classified, according to their age, sex, operating time, AO classification, open fractures classification (Gustilo-Anderson classification), union time, rate of infection, mal-union and Olerud Molander Ankle Score. ${ }^{10,11}$ Chi square test and fishers two sided exact test were used to compare parameters between the two groups.

\section{RESULTS}

A total of 50 patients with distal tibia meta-diaphyseal fractures participated in our study and they were divided into 2 groups. Group-A (25 patients) treated with multi directional intra-medullary interlocking nail and group-B (25 patients) treated with minimally invasive plating.

Pre-operative characteristics of enrolled patients are given in Table 1.

Table 1: Base line data, pre fracture baseline data $(\mathrm{N}=\mathbf{5 0})$.

\begin{tabular}{|lll|}
\hline Characteristics & $\begin{array}{l}\text { Nailing } \\
\text { (Group A) }\end{array}$ & $\begin{array}{l}\text { Plating } \\
\text { (Group B) }\end{array}$ \\
\hline Mean age & 37.8 & 41.48 \\
\hline Sex (male: female) & $19: 6$ & $19: 6$ \\
\hline AO classification & & \\
\hline 43-A1 & 08 & 06 \\
\hline A2 & 17 & 17 \\
\hline A3 & 00 & 02 \\
\hline $\begin{array}{l}\text { Number of closed } \\
\text { fractures }\end{array}$ & 21 & 20 \\
\hline Number of open fractures & 04 & 05 \\
\hline Gustilo-Anderson classification & \\
\hline Type 1 & 03 & 02 \\
\hline Type 2 & 01 & 03 \\
\hline
\end{tabular}

Following table (Table 2) shows the results of Fischer exact test to study the correlation between OMAS score and variables which affects the functional outcome.

Among the variables, average duration of surgery $(\mathrm{p}=0.035)$, fracture union $(\mathrm{p}=0.042)$ bear significant effect on functional outcome OMAS score $(\mathrm{p}=001)$. In our study we found that all patients treated with multidirectional locked nailing had better results than patients treated with MIPO. 
Table 2: Post injury status.

\begin{tabular}{|c|c|c|c|}
\hline Characteristics & Group A & Group B & P value \\
\hline Average duration between injury and surgery (days) & 2.84 & 2.20 & 0.226 \\
\hline Average duration of surgery (min) & 81 & 87 & 0.035 \\
\hline Full weight bearing mobility (weeks) & 11.48 & 12.96 & 0.001 \\
\hline Fracture union (weeks) & 19.60 & 20.71 & 0.042 \\
\hline Non union & 00 & 00 & 00 \\
\hline Delayed union & 00 & 00 & 00 \\
\hline Mal-union & 00 & 01 & - \\
\hline Superficial skin infection & 01 & 02 & _- \\
\hline Deep infection & 00 & 01 & - \\
\hline Implant failure & 00 & 01 & 0.5 \\
\hline \multicolumn{4}{|l|}{ Functional outcome (OMAS) } \\
\hline Mean & 92.80 & 85.10 & \multirow{4}{*}{0.00} \\
\hline Excellent & 09 & 11 & \\
\hline Good & 16 & 13 & \\
\hline Fair and poor & 00 & 00 & \\
\hline
\end{tabular}

Following table (Table 2) shows the results of Fischer exact test to study the correlation between OMAS score and variables which affects the functional outcome.

Among the variables, average duration of surgery $(\mathrm{p}=0.035)$, fracture union $(\mathrm{p}=0.042)$ bear significant effect on functional outcome OMAS score $(p=001)$. In our study we found that all patients treated with multidirectional locked nailing had better results than patients treated with MIPO.

\section{DISCUSSION}

Distal tibia fractures remains to be one of the most controversial fractures that we come across in the management. Surgeon's main aim is to get a decent reduction with minimal post-operative complications. To get these results minimal invasive plating and multidirectional locked intra-medullary nailing are the two viable options. In our study all patients who underwent nailing or plating return back to full weight bearing capacity except one patient, who was treated with MIPPO, had implant failure for which implant removal was done, followed by internal fixation with nailing and bone grafting. When compared to minimal invasive plating, multidirectional locked nailing technique has exhibited many advantages in terms of duration of surgery, union time, range of motion at ankle joint, early weight bearing capacity and lesser complications like wound infection, delayed union and non-union. Disadvantages with conventional intra-medullary nailing are difficulty to stabilize the distal fragment and malunion. To overcome these problems many techniques have come into existence like poller screws and angle stable locking screws. ${ }^{12,13}$ By introducing newer generation of intra-medullary nails (multidirectional locked nailing), which has both proximal and distal ends of multidirectional locked nailing system and have various locking options available in different planes, its usage in the management of distal tibia fractures is increased. Stability of the fracture fragments both axial and lateral will be augmented by angular stability locking system. ${ }^{14}$ Four locking options are available at distal end: one oblique (distal most), two medio-lateral and one antero-posterior which will increase the bone purchase and distal fragment stability. ${ }^{15,16}$ A meta-analysis study of 489 patients managed with conventional intra-medullary nailing with uni-planar screws showed mal alignment of 16-20\%. ${ }^{17}$ Studies done by Nork and others show decreased rate of mal-union in patients with fractures of the distal tibia metaphyseal region managed with three screws in various planes $(8 \%){ }^{6}$

Average time taken for surgery in group A (nailing) is 81 min where as in group B (plating) is $87.80 \mathrm{~min}$ and it suggests that there is significant difference in both groups $(p=0.035)$. There is a significant change seen in between two groups regarding weight bearing mobilization. In patients operated with nailing, full weight bearing mobilization started at an average 11.48 weeks where as in plating group full weight bearing mobilization started at 12.96 weeks.

Literature shows rate of delayed union and non union in patients with closed tibial fractures is $0-11 \%$ and $0-8 \%$ respectively, where as in open fractures from $9-47 \%$ and $3-17 \% .^{18,19}$ In our study there is no non union seen in the two groups.

Average time taken for fracture union in patients treated with multidirectional locked nailing is 19.60 weeks, and in patients treated with plating is 20.71 weeks and the difference between nailing and plating group is statistically significant $(\mathrm{p}=0.42)$. Im and Tae did a comparative study regarding wound complications in patients treated with intra-medullary nailing and plating and observed that wound complications are significantly higher in plating group than nailing group (7 out of 30 
patients in plating group versus 1 out of 34 in nailing group; $\mathrm{p}=0.03) .{ }^{20}$ Our results are comparable with above study; Post-operative complications are seen more in patients treated with plating (two superficial skin infections and one deep infection) while only one superficial skin infection seen in patients treated with intra-medullary nailing. All superficial skin infections are treated with regular dressing and antibiotics, whereas wound debridement done for deep infections.

Cheng et al done a comparative study between patients having distal tibia fractures treated with MIPO and conventional open reduction with plate fixation and observed a significantly high rate of implant irritation complaints in patients operated with MIPO than open technique. $^{21}$ In our study three patients complained of hardware irritation in plating group.

Guo et al done a prospective randomized control study in 85 patients with fractures of the distal tibia treated with either MIPO or intra-medullary nailing (41 patients with plating and 44 patients with nailing) and observed that all are united without any significant difference in functional score. ${ }^{22}$ Im Gi et al study in distal tibia fractures shows a significantly better range of motion seen in patients who were treated with nailing than plating. ${ }^{20}$ Our study results are comparable with above study. There is a high significant change seen in functional outcome (OMAS) between two groups, the mean OMAS is $92.80 \pm 4.89$ in patients treated with multidirectional locked nailing and $85.10 \pm 5.90(\mathrm{p}=0.000)$.

In literature, screw back out and anterior knee pains are the common reported complications seen in patients treated with intra-medullary nailing. ${ }^{23}$ In our study, there is no screw back out seen in nailing group but two patients have complained of occasional anterior knee pain.

One group B patient had implant failure (broken plate), possibly due to early weight bearing and he was treated with implant removal and later open reduction and fixation with IMIL nail followed by bone grafting. There is no implant failure seen in nailing group.

More secondary procedures are required in plating group when compared with nailing group. One patient required wound debridement and the other patient required revision surgery (ORIF with nailing, bone grafting) due to implant failure.

Use of both multidirectional locked nailing and minimal invasive plating is associated with increased rate of union and shows advantage in taking care about soft tissue around the fracture site. Limitations of our study include small sample size and minimal follow up.

\section{CONCLUSION}

These results proved that both multidirectional locked nailing and minimal invasive plating can be used in distal tibia fractures without any harm. Fracture pattern, clinical circumstances and surgeon skills should be considered before deciding the mode of management. Multidirectional locked nailing is considered as the preferable surgical option compared to minimal invasive plating because there are many advantages like decreased operative time, union time, early weight bearing and minimal wound complications with excellent functional outcome.

\section{Funding: No funding sources}

Conflict of interest: None declared

Ethical approval: The study was approved by the institutional ethics committee

\section{REFERENCES}

1. Fan CY, Chiang CC, Chuang TY, Chiu FY, Chen TH. Interlocking nails for displaced metaphyseal fractures of distal tibia. Int $\mathbf{J}$ Care Injured. 2005;36:669-74.

2. Ovadia DN, Beals RK. Fractures of tibial plafond. J Bone Joint Surg Am. 1986;68:543-51.

3. Robinson CM, McLauchlan GJ, McLean IP, CourtBrown CM. Distal metaphyseal fractures of the tibia with minimal involvement of the ankle. Classification and treatment by locked intramedullary nailing. $\mathrm{J}$ Bone Joint Surg Br. 1995;77:781-7.

4. Williams TM, Marsh JL, Nepola JV, DeCoster TA, Hurwitz SR, Bonar SB. External fixation of tibial plafond fractures: is routine plating of the fibula necessary? J Orthop Trauma. 1998;12:16-20.

5. Dogra AS, Ruiz AL, Thompson NS, Nolan PC. Diametaphyseal distal tibial fractures - treatment with a shortened intramedullary nail: a review of 15 cases. Int J Care Injured. 2000;31:799-804.

6. Nork SE, Schwartz AK, Agel J et al. Intramedullary nailing of distal metaphyseal tibial fractures. J Bone Joint Surg Am.2005;87: 1213-21.

7. Egol KA, Weisz R, Hiebert R, Tejwani NC, Koval KJ, Sanders RW. Does fibular plating improve alignment after intramedullary nailing of distal meta- physeal tibia fractures? J Orthop Trauma. 2006;20:94-103.

8. Blick SS, Brumback RJ, Lakatos R, Poka A, Burgess AR. Early bone grafting of high-energy tibial fractures. Clin Orthop Relat Res. 1989;240:21-41.

9. Bong MR, Kummer FJ, Koval KJ, Egol KA. Intramedullary nailing of the lower extremity: Biomechanics and biology. J Am Acad Orthop Surg. 2007;15(2):97-106.

10. Olerud C, Molander H. A scoring scale for symptom evaluation after ankle fracture. Arch Orthop Trauma Surg. 1984;103:190-4.

11. Gustilo RB, Anderson JT. The prevention of infection in treatment of 1000 and 25 open fractures of long bones - retrospective and prospective analysis. J Bone Joint Surg Am. 1976;58(4):453-8. 
12. Krettek C, Stephan C, Schandelmaier P, Richter M, Pape HC, Miclau T. The use of Poller screws as blocking screws in stabilising tibial fractures treated with small diameter intramedullary nails. J Bone Joint Surg Br. 1999;81(6):963-8.

13. Horn J, Linke B, Höntzsch D, Gueorguiev B, Schwieger K. Angle stable interlocking screws improve construct stability of intramedullary nailing of distal tibia fractures: A biomechanical study. Int J Care Injured. 2009;40(7):767-71.

14. Ibrahimi AE, Shimi M, Daoudi A. Intramedullary nailing in the management of distal tibial fractures. Current Orthopaedic Practice. 2009;20(3):300-3.

15. Dhakar A, Annappa R, Gupta M, Harshwardhan H, Kotian P, Suresh PK. Minimally Invasive Plate Osteosynthesis with Locking Plates for Distal Tibia Fractures. JCDR. 2016;10(3):1-4.

16. Gueorguiev B, Ockert B, Schwieger K, Wahnert D, Lawson-Smith $\mathrm{M}$, Windolf $\mathrm{M}$, et al. Angular stability potentially permits fewer locking screws compared with conventional locking in intramedullary nailed distal tibia fractures: a biomechanical study. J Orthop Trauma. 2011;25(6):340-6.

17. Zelle BA, Bhandari M, Espiritu M, Koval KJ, Zlowodzki M. Evidence-Based Orthopaedic Trauma Working Group: Treatment of distal tibia fractures without articular involvement: A systematic review of 1125 fractures. J Orthop Trauma. 2006;20(1):769.

18. Bonatus T, Olson SA, Lee S, Chapman MW. Non reamed locking intra-medullary nailing for open fractures of the tibia. Clin Orthop Relat Res. 1997;339:58-64.

19. Singer RW, Kellam JF. Open tibialdiaphyseal fractures. Results of unreamed locked intramedullary nailing. Clin Orthop Relat Res. 1995;315:114-8.

20. Im GI, Tae SK. Distal metaphyseal fractures of tibia: A prospective randomized trial of closed reduction and intramedullary nail versus open reduction and plate and screws fixation. J Trauma Injury Infection Critical Care. 2005;59(5):1219-23.

21. Cheng W, Li Y, Manyi W. Comparison study of two surgical options for distal tibia fracture-minimally invasive plate osteosynthesis vs. open reduction and internal fixation. Int Orthop. 2011;35(5):737-42.

22. Guo JJ, Tang N, Yang HL, Tang TS. A prospective, randomised trial comparing closed intramedullary nailing with percutaneous plating in the treatment of distal metaphyseal fractures of the tibia. J Bone Joint Surg Br. 2010;92(7):984-8.

23. Boenisch UW, de Boer PG, Journaeux SF. Unreamed intramedullary tibial nailing-fatigue of locking bolts. Int J Care Injured. 1996;27:265-70.

Cite this article as: Pinnaka $B$, Shankarlinga $S$, Kamath KR, Danda R, Raju MG. A comparative study of low multidirectional locked nailing and locking compression plating in management of distal tibia fractures. Int J Res Orthop 2018;4:830-4. 